\title{
Luteinizing hormone-releasing hormone antagonists for urinary obstruction in prostate cancer
}

\author{
Patricia Tai, MB BS; Asim Amjad, MD; Rashmi Koul, MD; Evgeny Sadikov, MD; Arbind Dubey, MD
}

Department of Radiation Oncology, Allan Blair Cancer Centre, Regina, SK

Cite as: Can Urol Assoc J 2013;7(9-10):e648-50. http://dx.doi.org/10.5489/cuaj.412 Published online October 9, 2013.

\section{Abstract}

Luteinizing hormone-releasing hormone (LHRH) antagonists rapidly reduce testosterone and are preferred to LHRH agonists in situations when early response is important. The lack of flare reaction, as compared to LHRH agonists, is particularly desirable as it would not aggravate the problem. A 78-year-old man presented with symptoms of urinary tract obstruction. He had a prostate-specific antigen (PSA) of $91.3 \mathrm{ug} / \mathrm{L}$ and serum creatinine $146 \mathrm{umol} / \mathrm{L}$. He had a large pelvic mass due to histologically confirmed prostate cancer, resulting in moderate left hydronephrosis and deteriorating renal function (serum creatinine of $163 \mathrm{umol} / \mathrm{L}$ ). He was started on combined degarelix and bicalutamide on the day of consultation (day 0 ). The hydronephrosis resolved on the repeat computerized tomography scan performed on day 10 . Serum creatinine normalized to under $130 \mathrm{umol} / \mathrm{L}$ on day 18 . The PSA fell to $11 \mathrm{ug} / \mathrm{L}$ on day $18,2.8 \mathrm{ug} / \mathrm{L}$ on day 28 , and $0.5 \mathrm{ug} / \mathrm{L}$ on day 53 . Therefore, $\mathrm{LHRH}$ antagonists are particularly useful in urgent situations. It is the preferred choice in these circumstances.

\section{Introduction}

Patients with advanced prostate cancers are treated with androgen deprivation therapy (ADT) with or without radiotherapy. For many years, orchiectomy or luteinizing hormone-releasing hormone (LHRH) agonists have been used. LHRH antagonists, such as degarelix, have been developed as they rapidly reduce testosterone and are preferred to LHRH agonists in situations when early response is important. The lack of flare reaction, as compared to LHRH agonists, is particularly desirable as it would not aggravate the problem (e.g., spinal cord compression, bone pain or urinary obstruction). With our patient, we decided to treat his prostate cancer with degarelix to improve his deteriorating renal function due to urinary tract obstruction.

\section{Case report}

A 78-year-old male presented with stage IV carcinoma of the prostate, T4NOMO. He had stomach discomfort for 1.5 months and lower urinary tract obstructive symptoms for 2 months. The family doctor did some blood tests and found that the prostate-specific antigen (PSA) was $91.3 \mathrm{ug} / \mathrm{L}$. A prostate biopsy showed an adenocarcinoma of Gleason score $9(5+4)$. Transrectal ultrasound showed a large mass above the base of the prostate.

Due to an elevated serum creatinine of $146 \mathrm{umol} / \mathrm{L}$ 3 weeks before, an urgent renal function and non-enhanced computerized tomography (CT) scan of the abdomen and pelvis were performed on the day of consultation. Serum creatinine came back to be $163 \mathrm{umol} / \mathrm{L}$. His CT scan showed a large lobulated pelvic mass which indented the bladder base and the anterior wall of the rectum (Fig. 1). It extended to the left pelvic sidewall in contact with the obturator internus muscle. The seminal vesicles could not be discerned. The mass measured $8.3 \times 8.1 \mathrm{~cm}$. No enlarged nodes were present more superiorly in the pelvis and there was no retroperitoneal nodal enlargement. There was moderate left hydronephrosis and hydroureter which could be traced to the level of the large prostatic pelvic mass (Fig. 2). There was no right hydronephrosis.

Degarelix $240 \mathrm{mg}$ subcutaneously and bicalutamide $50 \mathrm{mg}$ oral once daily for 2 weeks were started on the same day of new patient consultation (day 0). The radiologist felt that it would be quite difficult to insert a nephrostomy tube. During the multidisciplinary round, the urologist concluded that ADT generally would not work very fast and he intended to put a nephrostomy tube after seeing him. Partly to monitor the response and if possible to avoid an invasive procedure, a repeat $\mathrm{CT}$ was performed on day 10 post-ADT. The tumour had decreased in size to $7.1 \times 5.6 \mathrm{~cm}$ (Fig. 3), and the left renal collecting system was no longer distended (Fig. 4).

Upper endoscopy did not show any specific stomach or duodenal lesions. Serum creatinine, which was monitored 


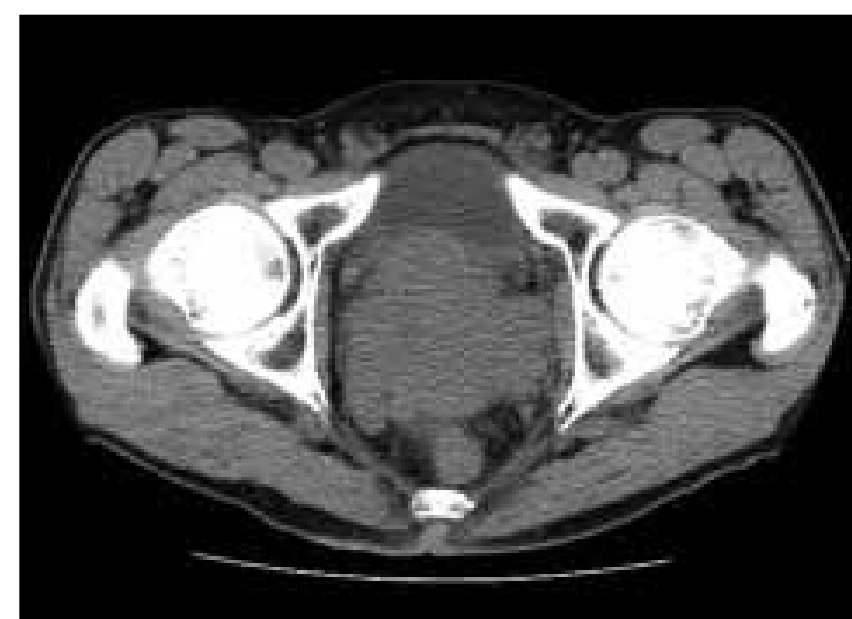

Fig. 1. Computerized tomography scan at the level of prostate on day 0 .

daily in the first week, normalized to below $130 \mathrm{umol} / \mathrm{L}$ on day 18 . The PSA fell to $11 \mathrm{ug} / \mathrm{L}$ on day $18,2.8 \mathrm{ug} / \mathrm{L}$ on day 28 , and $0.5 \mathrm{ug} / \mathrm{L}$ on day 53 . Testosterone was measured on day 28 and already achieved $<20 \mathrm{ng} / \mathrm{dL}(0.69 \mathrm{nmol} / \mathrm{L})$. He then received monthly maintenance doses of degarelix $80 \mathrm{mg}$ subcutaneously.

\section{Discussion}

Degarelix was chosen as the treatment for this patient due to its rapid onset of action and lack of flare. Klotz and colleagues made these observations in the CS21 study, a 12-month open-label randomized study on the use of degarelix $240 \mathrm{mg}$ for 1 month then maintenance 80 or $160 \mathrm{mg}$ versus $7.5 \mathrm{mg}$ leuprolide monthly in different stages of prostate cancer. ${ }^{1}$ Three days after starting treatment, the median testosterone levels were $\leq 0.5 \mathrm{ng} / \mathrm{mL}$ in $96.1 \%$ and $95.5 \%$ of patients in the degarelix 240/80 $\mathrm{mg}$ and 240/160 mg groups, respectively. Some patients in the leuprolide group had testosterone surge; the median testosterone levels increased by $65 \%$ from baseline by day $3(6.30 \mathrm{ng} / \mathrm{mL})$. Of the 201 patients

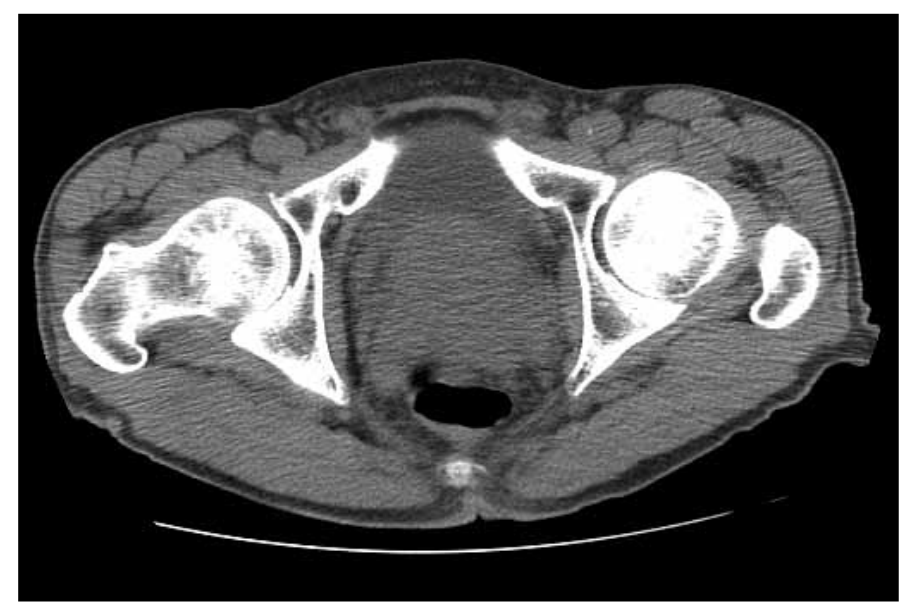

Fig. 3. Computerized tomography scan at the level of prostate on day 10.

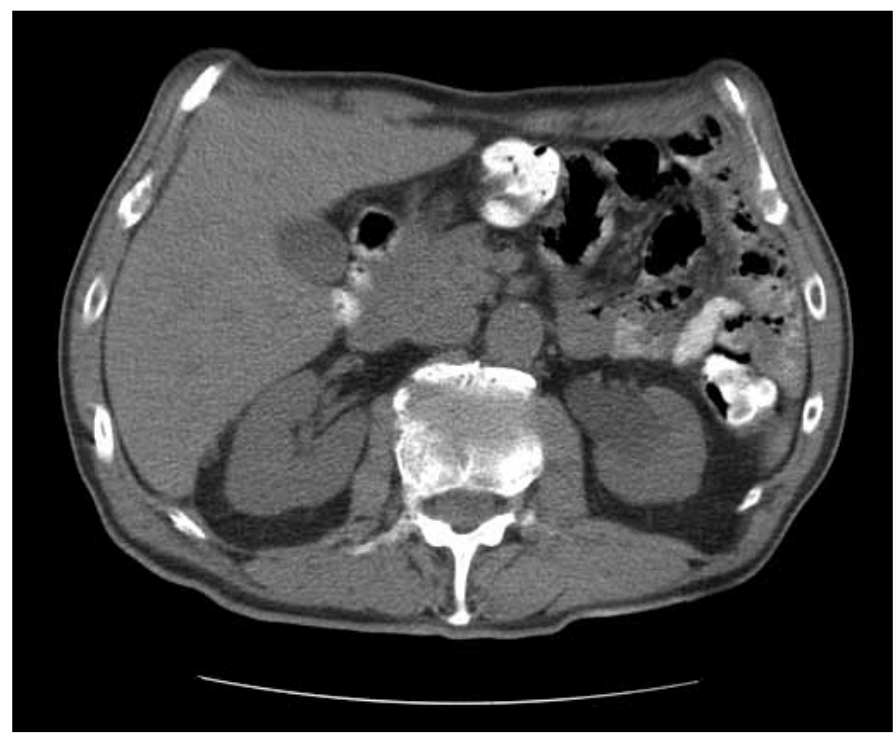

Fig. 2. Computerized tomography scan at the level of kidneys on day 0 .

in the leuprolide group, $23(11 \%)$ received concomitant bicalutamide for flare protection at the start of treatment. Of the 178 patients in the leuprolide group who did not receive bicalutamide, $144(81 \%)$ had a surge in testosterone (defined as a testosterone increase of $\geq 15 \%$ from baseline, on any 2 days during the first 2 weeks). In patients who received bicalutamide, 17/23 (74\%) had a testosterone surge. PSA was suppressed significantly more rapidly by degarelix at day 14 and 28.

There are other potential advantages of degarelix over LHRH analog. Firstly, compared to leuprolide, it provides a better control of the bone formation marker serum alkaline phosphatase (ALP) in patients with metastatic disease. ${ }^{2}$ Secondly, Pickles and colleagues described the problem of incomplete testosterone suppression with LHRH agonists;

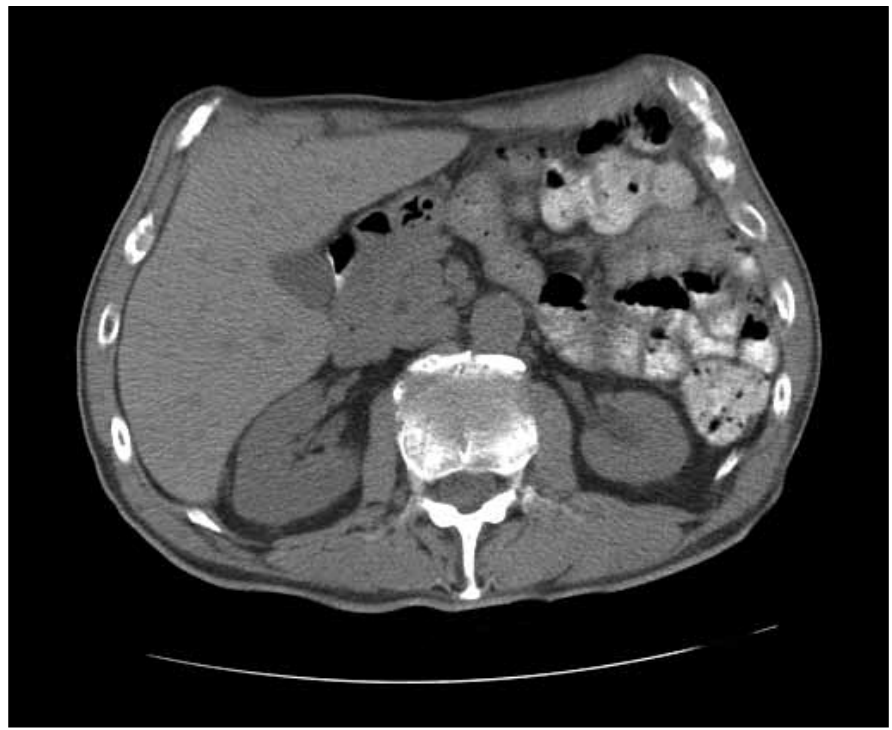

Fig. 4. Computerized tomography scan at the level of kidneys on day 10. 
Tai et al.

Table 1. LHRH antagonists are preferred to LHRH agonists in these cases

- Spinal cord compression (to avoid flare reaction)

- Urinary tract obstruction especially for severe symptoms/renal impairment/ hydronephrosis (to avoid flare reaction)

- Advanced PCa who failed to achieve castrate levels of testosterone while on an LHRH agonist.

- Rapid shrinkage of prostate gland prior to brachytherapy

- Metastatic PCa (since the skeletal-related events are less than LHRH agonist)

- PSA more than $20 \mathrm{ug} / \mathrm{L}$

LHRH: luteinizing hormone-releasing hormone; PCa: prostate cancers; PSA: prostate-specific antigen.

the risk of a breakthrough $>32 \mathrm{ng} / \mathrm{dL}(1.1 \mathrm{nmol} / \mathrm{L})$ was $6.6 \%$, and $>50 \mathrm{ng} / \mathrm{dL}(1.7 \mathrm{nmol} / \mathrm{L})$ was $3.4 \% .^{3}$ Repeated breakthroughs occurred in $16 \%$ of patients. The 5 -year biochemical no evidence of disease (bNED) duration was inferior in those with breakthroughs of 1.1 to $1.7 \mathrm{nmol} / \mathrm{L}$ versus those without ( $58 \%$ vs. $73 \%$, respectively; $p=0.048)$. Tombal and colleagues also reported that about $5 \%$ to $17 \%$ patients on LHRH agonists fail to achieve a castrate testosterone of $50 \mathrm{ng} / \mathrm{dL}(1.7 \mathrm{nmol} / \mathrm{L})$ or less. ${ }^{4}$ These are clinically relevant as there is a relationship between testosterone suppression and androgen-independent progression; breakthrough testosterone increases predict decreased progression-free survival (PFS). ${ }^{5}$ Lastly, the extension study (CS21A) showed that follicle-stimulating hormone ( $\mathrm{FSH})$ suppression was better with degarelix. ${ }^{6}$

The disadvantages of degarelix include a $40 \%$ rate of injection site reactions, ${ }^{1}$ cost and inconvenience to patients and staff due to the monthly injection requirement. Table 1 summarizes the current indications for LHRH antagonists. Our case illustrates the advantages of degarelix. In retrospect, the lack of flare with degarelix obviates the need of anti-androgen supplements in our case.

There are currently no long-term data on survival differences between therapy with degarelix and LHRH agonists. The number of deaths in CS21 is too small to draw any definite conclusions. The published report of CS21A has a median 27.5 month follow-up only. ${ }^{6}$ However, this is a 5 -year extension to the pivotal trial and is ongoing to investigate the long-term safety and efficacy of degarelix.

\section{Conclusion}

In emergency situations like spinal cord compression, the lack of flare reaction and rapid response of testosterone within 3 days are distinct advantages over LHRH analogs. Our case illustrates that degarelix can avoid more invasive procedures, like nephrostomy tube insertion or Foley catheterization in patients with urinary obstruction. LHRH antagonists are particularly useful in urgent and emergency situations. It is the preferred choice in these circumstances.

Competing interests: None declared.

This paper has been peer-reviewed.

\section{References}

1. Klotz L, Boccon-Gibod L, Shore ND, et al. The efficacy and safety of degarelix: a 12-month, comparative, randomized, open-label, parallel-group phase III study in patients with prostate cancer. BJU Int 2008;102:1531-8. http://dx.doi.org/10.1111/j.1464-410X.2008.08183.x

2. Tombal B, Miller K, Boccon-Gibod L, et al. Additional analysis of the secondary end point of biochemical recurrence rate in a Phase 3 trial (CS21) comparing degarelix $80 \mathrm{mg}$ versus leuprolide in prostate cancer patients segmented by baseline characteristics. Eur Urol 2010;57:836-42. http://dx.doi.org/10.1016/i. eururo.2009.11.029

3. Pickles T, Hamm J, Morris WJ, et al. Incomplete testosterone suppression with luteinizing hormone-releasing hormone agonists: does it happen and does it matter? BJU Int 2012;110(11 Pt B):E500-7. http:// dx.doi.org/10.1111/.j.1464-410X.2012.11190.x

4. Tombal B and Berges R. How good do current LHRH agonists control testosterone? Can this be improved with Eligard@? Eur Urol 2005;4S:30.

5. Morote J, Orsola A, Planas J, et al. Redefining clinically significant castration levels in patients with prostate cancer receiving continuous androgen deprivation therapy. J Urol 2007;178:1290-5. http:// dx.doi.org/10.1016/i.juro.2007.05.129

6. Crawford ED, Tombal B, Kurt Miller K, et al. A phase III extension trial with a l-arm crossover from leuprolide to degarelix: comparison of gonadotropin-releasing hormone agonist and antagonist effect on prostate cancer. J Urol 2011;186:889-97. http://dx.doi.org/10.1016/i.juro.2011.04.083

Correspondence: Dr. Patricia Tai, Department of Radiation Oncology, Allan Blair Cancer Centre, 4101 Dewdney Ave., Regina, SK S4T 7T1; fax: 306-766-2845; ptai2@yahoo.com 